\title{
Peripheral retinal arteriolar leakage in giant cell arteritis: a case report
}

\author{
Meleha Ahmad, Andrew R. Carey, Charles G. Eberhart, Sepideh Siadati and Amanda D. Henderson*
}

\begin{abstract}
A 76-year old African American female with a history of arteritic ischemic optic neuropathy (AION) secondary to biopsy-proven giant cell arteritis (GCA) presented with unilateral vision loss in her contralateral eye despite highdose oral steroid treatment. Dilated fundus examination revealed three cotton wool spots. Fluorescein angiography showed slowed arteriolar filling with late staining of small peripheral arteries, consistent with small vessel arteritis. Laboratory tests for alternative vasculitides were negative. Review of her temporal artery biopsy specimen confirmed lymphoplasmacytic inflammation around small adventitial vessels with no destructive granulomatous or leukocytoclastic small vessel vasculitis, consistent with GCA. Our unique case demonstrates peripheral small vessel retinal arteriolar leakage in GCA, which is a rare finding. This association is of interest because GCA is commonly associated with medium to large vessel pathology without small vessel involvement.
\end{abstract}

Keywords: Case report, Cotton wool spot, Giant cell arteritis, Retinal arteriolar leakage, Retinal vascular leakage, Temporal arteritis, Vasculitis

\section{Presentation}

A 76-year-old woman with a history of hypertension, non-insulin dependent type 2 diabetes, stroke, and arteritic ischemic optic neuropathy (AION) of the left eye due to biopsy-proven giant cell arteritis (GCA) presented with painless, diffuse vision loss in the right eye for the past 10 days despite current high-dose oral steroid treatment $(0.75 \mathrm{mg} / \mathrm{kg} /$ day prednisone). Diabetes and hypertension were controlled with a recent hemoglobin A1c of $6.4 \%$ and blood pressure of 122/74 at recent outpatient visit. Uncorrected visual acuity was decreased from her baseline of 20/40 to 20/70 in the right eye with no improvement with pinhole. Slit lamp examination of the anterior segment was unremarkable except for $2+$ nuclear sclerotic cataract and $1+$ cortical cataract in the right eye; the left eye was pseudophakic. There was no evidence of inflammation of the anterior or posterior segment of either eye. Dilated fundus examination showed two cotton wool spots in the right eye (Fig. 1a), which had not been noted

\footnotetext{
* Correspondence: Ahende24@jhmi.edu
}

Division of Neuro-Ophthalmology, Wilmer Eye Institute, Johns Hopkins

University School of Medicine, 600 N Wolfe Street, Baltimore, MD 21287, USA on recent dilated fundus examinations; there was optic nerve pallor in the left eye in the setting of prior AION (Fig. 1b). Fluorescein angiography demonstrated patchy choroidal non-perfusion and slowed arteriolar filling in the early phase in the right eye (Fig. 1d), likely contributing to her decreased visual acuity, with late peripheral arteriolar leakage in this eye (Fig. 1e) and areas of choroidal non-perfusion in the left eye (Fig. 1f). Inflammatory markers, including erythrocyte sedimentation rate (ESR) and C-reactive protein (CRP), were normal for age. She was treated with high dose intravenous steroids (1 $\mathrm{g}$ solumedrol daily $\times 5$ days) followed by $1 \mathrm{mg} / \mathrm{kg} /$ day oral prednisone with a slow taper. Workup for other causes of small vessel vasculitis, including anti-neutrophil cytoplasmic antibodies (ANCA), antinuclear antibodies (ANA), lyme and syphilis serologies, was negative. Review of her medications failed to demonstrate any known pharmaceuticals associated with retinal vasculitis or intraocular inflammation. Her temporal artery biopsy specimen demonstrated destructive granulomatous infiltration of the adventitia, media and intima, along with lymphoplasmacytic inflammation around small adventitial vessels without destructive granulomatous or leukocytoclastic

\section{Springer Open}

(c) The Author(s). 2021 Open Access This article is licensed under a Creative Commons Attribution 4.0 International License, which permits use, sharing, adaptation, distribution and reproduction in any medium or format, as long as you give appropriate credit to the original author(s) and the source, provide a link to the Creative Commons licence, and indicate if changes were made. The images or other third party material in this article are included in the article's Creative Commons licence, unless indicated otherwise in a credit line to the material. If material is not included in the article's Creative Commons licence and your intended use is not permitted by statutory regulation or exceeds the permitted use, you will need to obtain permission directly from the copyright holder. To view a copy of this licence, visit http://creativecommons.org/licenses/by/4.0/. 


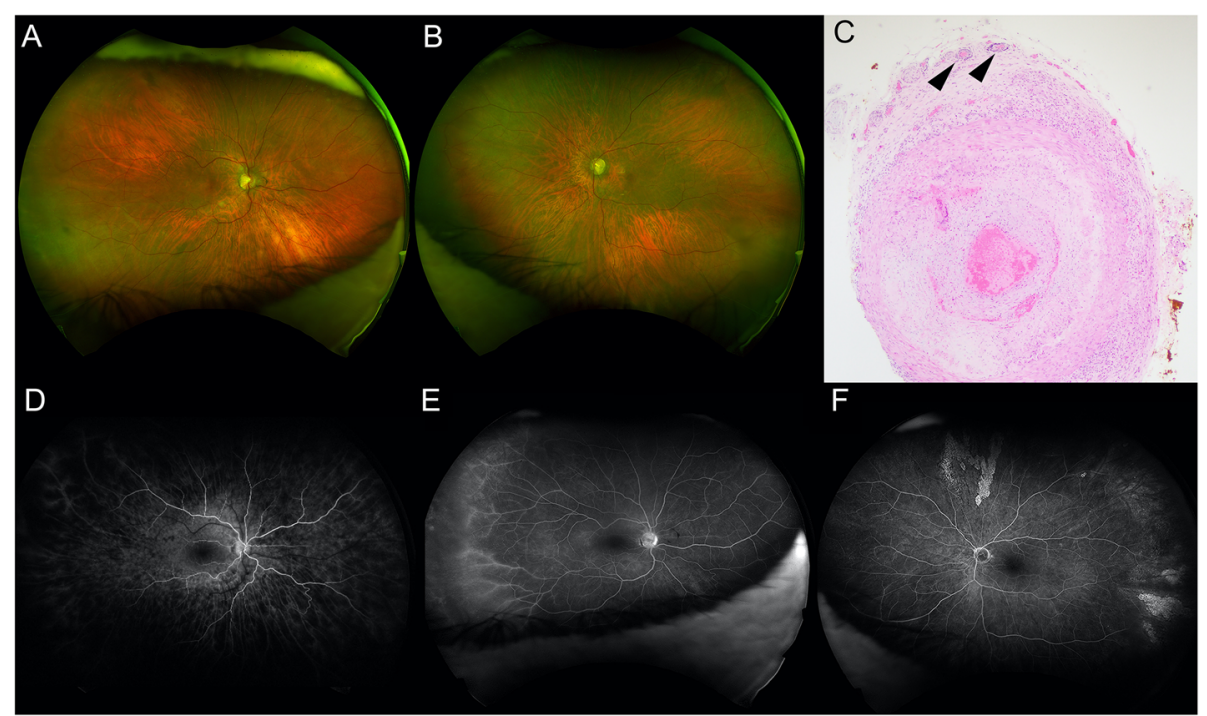

Fig. 1 a Wide field color fundus photograph of the right eye showing cotton wool spots. $\mathbf{b}$ : Wide field color fundus photograph of the left eye showing optic nerve pallor and narrowing of the retinal vessels. $\mathbf{d}$ : Wide field early-frame fluorescein angiography of the right eye showing delayed arteriolar filling and patchy choroidal filling. e: Wide field late-frame fluorescein angiography of the right eye showing staining of peripheral small retinal arterioles. f: Wide field early-frame fluorescein angiography of the left eye showing patchy choroidal filling defects but no late arteriolar staining. $\mathbf{c}$ : Temporal artery biopsy demonstrating destructive granulomatous infiltration of the adventitia, media and intima with lymphoplasmacytic inflammation present around small adventitial vessels (arrows)

small vessel vasculitis, consistent with GCA without evidence of additional vasculitides (Fig. 1c). Steroids were tapered, she was started on tocilizumab by her rheumatologist, and her visual acuity stabilized.

\section{Discussion}

Common retinal ischemic lesions in GCA include central retinal artery occlusion, choroidal ischemic lesions and cotton wool spots (CWS) [1]. These ocular findings are caused primarily by medium vessel vasculitis, except for CWS whose pathogenesis in GCA remains poorly understood. Given the presence of new CWS despite well-controlled diabetes and hypertension, as well as classic findings of GCA in the contralateral eye, the patient's CWS were felt to be most likely related to GCA rather than other comorbidities such as diabetes and hypertension. Two potential mechanisms for CWS in GCA include local factors, such as elevated fibrinogen levels, contributing to transient retinal microvascular occlusion [2] as well as retrograde or orthograde axoplasmic flow due to upstream occlusion of medium-sized vessels of the posterior ciliary or retinal circulations [3].

Florid retinal vascular leakage and retinal vasculitis are less well described in GCA, with only one prior case reported in the literature (search was conducted using Pubmed database with no language restrictions using keywords: "giant cell arteritis", "temporal arteritis", "vasculitis", "retinal vascular leakage"). Papakostas, et al. described a 75-year old man presenting with subjective blurred vision, with examination demonstrating bilateral CWS, vascular sheathing, and extensive vasculitis with areas of non-perfusion in the more severely affected eye. The patient was diagnosed with GCA based on temporal artery biopsy, with the authors proposing a common pathogenic cause between fundus and temporal artery biopsy findings [4]. Although, strictly speaking, retinal vasculitis requires direct biopsy for definitive diagnosis, these cases of peripheral retinal arteriolar leakage could represent early small-vessel retinal vasculitis in GCA.

Outside of the eye, small vessel vasculitis in GCA has been visited in the pathology literature, with several groups identifying arterial vasculitis in extramural small vessels adjacent to the main temporal artery [5]. This finding may be seen in up to $70 \%$ of temporal artery biopsies and may signal a subtype of GCA with disparate clinical features [6]. The mechanism for small vessel involvement in these cases may be distinct from the mechanism occurring in vasculitis affecting distant sites such as the retina, such as a humoral or immunologic cause rather than direct spread or primary inflammatory cause. The recognition of a potential association between small vessel vasculitis and GCA could add further understanding to the pathogenesis of GCA, which is typically regarded as a large and medium vessel disease. 


\section{Abbreviations}

AION: Arteritic ischemic optic neuropathy; ANA: Antinuclear antibodies; ANCA: Anti-neutrophil cytoplasmic antibodies; CRP: C-reactive protein; CWS: Cotton wool spot; ESR: Erythrocyte sedimentation rate; GCA: Giant cell arteritis

\section{Acknowledgements}

None.

\section{Authors' contributions}

All authors contributed to project conception and critical review of manuscript. The author(s) read and approved the final manuscript.

\section{Funding}

None.

Availability of data and materials

Not applicable.

Ethics approval and consent to participate

Not applicable.

\section{Consent for publication}

Written informed consent for publication was obtained.

\section{Competing interests}

No author has any conflicts of interest to disclose.

Received: 1 November 2020 Accepted: 6 January 2021

Published online: 29 January 2021

\section{References}

1. Hayreh SS, Podhajsky PA, Zimmerman B (1998) Occult giant cell arteritis: ocular manifestations. Am J Ophthalmol 125(4):521-526

2. Melberg NS, Grand MG, Dieckert JP, Barney NP, Blumenkratz MS, Boone DE, Folk JC, Stransky TJ (1995) Cotton-wool spots and the early diagnosis of giant cell arteritis. Ophthalmology 102(11):1611-1614

3. McLeod D, Kohner EM (1996) Cotton-wool spots and giant cell arteritis. Ophthalmology 103(5):701-702

4. Papakostas TD, Jakobiec FA, Stagner AM, Eliott D, Kim LA (2016) Smallcaliber retinal vasculitis associated with giant cell arteritis: a new finding Ophthalmic Surg Lasers Imaging Retina 47(11):1054-1056

5. Rosenbaum JT, Sibley CH, Lin P (2016) Retinal Vasculitis. Curr Opin Rheumatol 28(3):228-235

6. Belilos E, Maddox J, Kowalewski RM, Kowalewska J, Turi GK, Nochomovittz LE, Khan Y, Carsons SE (2011) Temporal small-vessel inflammation in patients with giant cell arteritis: clinical course and preliminary immunohistopathologic characterization. J Rheumatol 38(2):331-338

\section{Publisher's Note}

Springer Nature remains neutral with regard to jurisdictional claims in published maps and institutional affiliations.

\section{Submit your manuscript to a SpringerOpen ${ }^{\circ}$ journal and benefit from:}

- Convenient online submission

- Rigorous peer review

- Open access: articles freely available online

High visibility within the field

- Retaining the copyright to your article 